\title{
Developing participation through digital reconstruction and communication of 'lost' heritage
}

\author{
Laura Loredana Micoli, Gabriele Guidi, Pablo \\ Rodríguez-Gonzálvez and Diego González-Aguilera
}

\section{Introduction}

We consider knowledge of urban history and cultural assets, especially among younger generations, as fundamental to the development of an understanding of a place and its identity, as well as to face the current challenges of heritage conservation. Public participation is at the forefront of planning heritage and cultural policy agendas (e.g., Faro Convention 2005; UNESCO 2011; ICOMOS 2018). Particular attention is dedicated to the different meanings, forms and effects of participation (Chiabai et al. 2013). In this chapter, we follow the 2009 UNESCO Framework for Cultural Statistics' definition of cultural participation:

cultural practices that may involve consumption as well as activities that are undertaken within the community, reflecting quality of life, traditions and beliefs. Moreover, cultural participation covers both active and passive behaviour. It includes the person who is listening to a concert and the person who practices music.

Another significant current theme is related to digital technologies that enable cultural innovation and participation (Ciasullo et al. 2016). In recent decades, digital media have changed the ways to operate in research, preservation, management, interpretation, representation, creation and access to cultural heritage (Cameron and Kenderdine 2007; Taylor and Gibson 2017). 
In the case studies presented in this chapter, we explore how digital tools can help active participation by citizens, and have a fundamental and concrete role in different phases of heritage research: in the initial phase of study and research, especially where citizens are owners of goods or custodians of information on assets, and in subsequent phases of representation of the results through digital media. Ethics considered, the use of results and tools by citizens can also provide quantitative and qualitative data that allow improvements to the contents and the communication tools.

This chapter presents two cases in which research involving citizen participation took place in various forms, using digital tools at various stages. The work was undertaken within the international research project 'Cultural Heritage Through Time' (CHT2). In this project, we developed a general methodology for creating 4D models (which are 3D models associated with different times) of cultural heritage assets, ranging from a building to an urban context or a landscape. The general purpose was to generate 4D digital models, revealing changes, through time, of the chosen heritage sites, and developing such methodology by maintaining an active collaboration with the stakeholders, mainly represented by the institutions in charge of management and conservation of the heritage assets under investigation.

Another aim of the project was to provide tools for effectively visualizing 4D models, capable of making the material accessible online, in order to share multi-temporal information on the web and to further accommodate public participation.

The two case studies, here presented, were located in Italy and Spain. The inhabitants living near the heritage assets got involved during the research phase by sharing their knowledge of the heritage site, allowing access to private properties involved in the research, and verifying the usability and impact of the digital products produced by the project. This active involvement worked as a catalyst, producing an amplifier effect in the project's visibility, and triggering greater public attention and involvement in later phases.

\section{Triggering public participation through 4D reconstruction of cultural heritage assets}

Memory has become a major preoccupation - in Europe and beyond - in the twentieth century and into the twenty-first ... Europe has become a memoryland obsessed with the disappearance of collective memory and its preservation. 
These words, which open the book Memorylands: Heritage and Identity in Europe Today, by the anthropologist MacDonald (2013), well summarize the current level of attention with respect to the cultural phenomenon of memory. Memory has also been labelled a 'metaphor of a physical location' and as such is intimately bound up in efforts to construct territory and place (Wright and Falconer 1998). However, such places do not carry meaning inherently but give their audience the capacity to make meaning (Buckley 1998). Our 4D models aim to develop further possibilities for people to produce and share such understandings and meanings.

Cultural heritage, tangible and intangible, is perceived as a public good (see, e.g., Fiorentini et al., this volume). The general question of quality interventions, and the complexity of involved stakeholders, disciplines and approaches, requires an integrated and participatory approach to safeguarding and managing cultural heritage (see, e.g., Moore and Tully and Veldpaus and Wacogne, this volume). Continuously monitoring cultural assets' state, for example, allows both evaluating their physical conservation and considering how they are perceived by the public, shaping new strategies for raising awareness of and participation in cultural heritage research. For some, tangible and visual elements of cultural landscape, such as buildings or monuments, play crucial roles as icons of cultural identity and determine a strong connection between the spatiality and history of places (McDowell 2008), while they can also exclude others from feeling that they belong (Anderson 1983; Hall 1999). Urban fabric represents an integral part of cultural heritage, and thus also shapes the senses of belonging somewhere (or not), of social traditions and cultural identity (Doulamis et al. 2018).

Furthermore, in heritage research, attention has shifted to emphasizing the immaterial nature of heritage and culture and the dissonance between various cultural expressions (Smith 2006). It has been noted that there can be a pluralistic notion of value according to a specific spatial, cultural and historical framework (Pendlebury 2009), and it has been underlined that heritage has to be intended, not as something fixed that is inherited from the previous generation, but as a fluid process always changing in relation to the present (Harrison 2013). With an awareness of critical heritage studies, here the idea of preservation is defined as protection from ageing and physical restoration of material heritage objects, and as an action aiming to safeguard their multiple symbolic meanings, old and new. Digital representation adds to this notion of preservation by offering different ways of interacting with the heritage and learning about its material and symbolic meanings, representing strong cultural identity elements. 
The history of a culturally significant site is not singular, and it tends generally to be blurred in the memory of people; such a site is often perceived as 'distant' in time and space. The site offers pieces of physical evidence through which people can enter into an emotional relationship in the present time, becoming a source of understanding(s) of the past as well as personal memories. 'The building where my school used to be ...', 'the Roman column close to which I hang out with my friends drinking a beer ...', 'the ancient portal that I used as the landmark for meeting with my fiancée ...' are just some of the examples we encountered of physical landmarks becoming part of everyday personal experiences.

\section{Case studies}

The $4 \mathrm{D}$ digital models generated by the project, in addition to 'technical' use related to conservation and urban planning, may be used as 'connectors' between something vividly present in someone's memory and historical content. Navigating such digital representations of artefacts allows us to virtually visit a place in different time periods, generating a 'time machine' effect that represents a powerful tool for linking history and space. This helps people to position the site where they live in a more general historical framework, possibly creating a stronger connection between them and their territories (G7 2017). The outcomes of the CHT2 project have shown that the relationship between past and present is an aspect that fascinates people and leads them to a broader approach to cultural heritage, increasing their sense of identity. The experiments conducted in the framework of the CHT2 project were carried out at several European sites, two of which, located in Italy and Spain, respectively, made the connection mentioned above particularly evident.

The first case concerns an important monument almost completely invisible to the untrained eye, located in Milan: the late Roman circus, an archaeological structure for chariot races, built when Milan was the capital of the Western Roman Empire (AD 286 to 402). Nowadays, the monument is almost unknown because only a few remains are visible; many others lie beneath the urban fabric. This is the case for many monumental buildings of the Roman period in Italian and other European cities: they have almost completely disappeared over time, being gradually dismantled and reused as construction materials elsewhere, making space for dense urbanization. As the remains of the past are only partially visible and hardly perceptible in their entirety, digital representation technologies are particularly useful, supporting investigation and visualization that leads to an understanding of cultural heritage and its 
connections with the contemporary city. Furthermore, the digital visualization of sites or monuments through time can help general audiences to build and add individual or collective cultural memory (Frischer 2014), without physically visiting the site. This last aspect is particularly significant as it shows how, when someone is able to identify the link between past and present through physical entities that are part of their personal experience, a process of identification with the specific site is triggered (Chiabai et al. 2013).

In the Milan case, the connection between diachronic views and public participation has been a constant leitmotif of all the work. The reconstruction through time was based on a mix of historical data and georeferenced geometric data. Since most of the monument's relics lie underground, accessible only from privately owned cellars, the first step in collecting geometric data was a capillary inspection in the area where the circus was expected to be. This meant examining a region of about $100 \times 500 \mathrm{~m}$ in the heart of the city, contacting the local residents and explaining the purpose of the research in order to gain access to their homes for the practical execution of the survey. The preliminary creation of a condition of trust towards the project team was crucial for getting the permission of the owners to enter the basements of their houses to identify the shape and position of the Roman circus ruins using laser scanners and other $3 \mathrm{D}$ technologies. Considering that in this way sensitive data were also collected, such as the structure of the house, it was necessary to clarify the use of such data in the framework of the project and to handle data protection with great care, always obtaining consent. Therefore, this progressive level of engagement at a personal level with the various individuals involved in this process - often represented directly by the owners of the buildings - generated an increasing interest in the project from several people living in that area, previously uninformed about the details of the relics contained under their houses.

The georeferenced 3D digitization of the remains still standing was the next step for the scientifically supported reconstruction of the monument. In addition, those who owned historical photographs of the area were asked to share them. Another interesting aspect was the gathering of oral testimonies from older residents who remembered the radical transformations that the area had suffered from the 1940s to the present, following the serious bombings of the Second World War and the subsequent phase of urban reconstruction. Older people remembered, for example, devastated buildings that showed portions of ancient archaeological remains in the subsoil areas, which are no longer visible today because they have been removed or covered by new buildings; or blocks with different shapes from the current ones. Subsequently, many citizens contacted for the research followed its development with great interest. At 
the end of the research project, an event was organized at the Archaeological Museum of Milan to present the results of the $3 \mathrm{D}$ diachronic reconstruction of the Roman circus and the area that housed it. This event had a large audience, including journalists, academics and the general public, a large part of which consisted of citizens of the area that had participated in the research. Subsequently, further dissemination events were organized, for example, in the schools of the district located where the circus used to be and in which the $3 \mathrm{D}$ digitization of the ruins had been carried out. Students were fascinated by the idea of daily frequenting a place on top of such a spectacular structure for chariot races, and also expressed experiencing a sense of greater belonging to the place.

In order to foster public participation in a project concerned with preservation and enhancement of cultural heritage, we recommend involving the area's residents from the earliest investigation phases. In this way, people feel part of the process of discovery and actively gain and contribute knowledge, as well as developing affection for the area and its cultural content.

In the case of the Milan Roman circus, collected data enabled an integrated interpretation of all the widespread archaeological pieces of evidence for a credible digital reconstruction of the monument as a whole. The correct placement of the circus in respect to the modern city allowed us to achieve a diachronic visualization of the urban area by connecting the shape of the modern city and its architecture with the ancient monument. The use of $4 \mathrm{D}$ reconstruction, as shown here (Figure 7.1), supports developing further understanding of changes that have occurred between the present and the past. Portions of the city become interpretable as the results of a historical process, while the availability of such knowledge facilitates comprehension.

This was evident at the public presentation of the project's results, where many of the owners of the basements containing the circus remains participated with great interest, proud of the role of their contribution to the project and sincerely curious about the final results. Such increased interest among the local inhabitants in the 'invisible' Roman circus gave tangible evidence that, for some people, knowing about the evolution of the place where they live provides an increased sense of belonging and the will to participate actively in such an evolutionary path. Also, this leads such residents to voluntarily commit themselves to becoming ambassadors active in the diffusion of such knowledge.

Moreover, 3D and 4D digital reproductions can be managed by museums or public administrations, both for on-site and online visualization. Using 3D-4D 


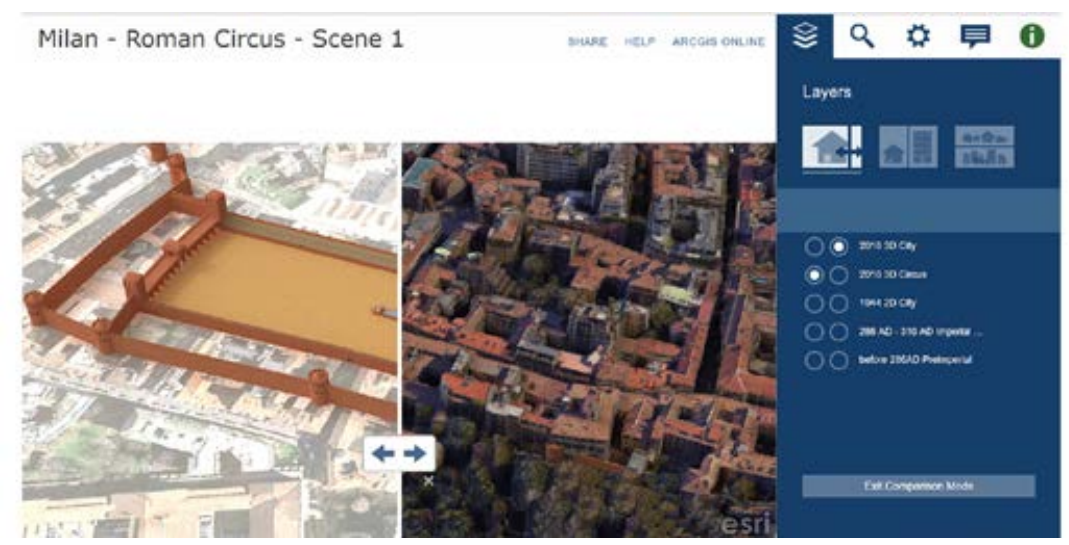

Source: Visible on the website https://cht2.eu/index.php/ONLINE-VISUALIZATION.

Figure 7.1 3D textured models of two historical moments: the circus in late Roman times (left) and the same area in the contemporary era (right) visualized through the CityEngine web viewer (ESRI, Redlands, CA, USA)

digital exploration, it is possible to acquire an awareness of the enormous evolution of an area over the centuries. All 3D representations of the project, which define the variations over time of the studied areas, are visible on the project website, which allows end-users to interact with 4D urban landscapes through a common web browser. Through this tool it is possible to explore maps, display specific layers for individual historical periods and enrich the experience with informative elements linked to hot spots on the model.

This allows for the dissemination of information on a cultural heritage site to a potentially very broad audience. In particular, tourists walking through the relevant city could enjoy the display of ancient monuments, possibly overlapped with the real city, by using augmented reality technologies.

For Ávila (Spain), the diachronic reconstruction of its medieval wall was focused on the citadel (Alcázar) and on some extramural buildings, which disappeared in 1882 and 1930, respectively. Since Ávila's case was selected for its lost assets (e.g., towers demolished and reconstructed elsewhere), the collection of historical sources implied an intense effort to extract the information needed - sometimes just textual and not supported by a graphical representation - and to translate it into detailed and visually rich $4 \mathrm{D}$ models. 
During the integration of historical and archaeological sources, several contradictory documents were discovered. The most significant case was related to the eighteenth-century plans (from two different authors), which gave different information about the internal structure and arrangement of the citadel. Thanks to old photographs (twentieth century) and written testimonies (nineteenth and twentieth centuries), it was possible not only to identify these errors, but also to avoid the creation of a false historical reconstruction.

The project, aimed at a diachronic reconstruction of the citadel prior to the mid-eighteenth century, was meant to face a challenge in terms of scarce reliable historical information. Since a virtual 3D reconstruction of a portion of a city like the one proposed here, in order to be believable, needs to show not only the specific monumental building that is the object of the research (i.e., the Alcázar) but also the surrounding urban fabric, historically based constructive hypotheses were employed to 'fill the gaps'. These hypotheses were based on similar medieval military constructions, considering construction techniques and tools available in that temporal frame.

For this case, we focused on the involvement of a test audience, for tool development. The diachronic model and the $4 \mathrm{D}$ visualizer were presented to a group of 24 end-users, ranging from tourists to specialized users such as heritage experts and government (planning) officers. The users interviewed agreed that $4 \mathrm{D}$ models raised their awareness about local cultural heritage. The diachronic models were considered a way to learn about history more effectively. It has to be emphasized that journalists, who were the most inquisitive regarding the results of the project (even at the initial stages), stated that they were better able to see the effective evolution and changes of the monument.

In relation to the dissemination of the results on the web, the feedback was positive, as the non-scientific public expressed its astonishment about the technology used for creating diachronic models. Some discussions were raised in relation to modifications carried out through history, for instance, the displacement of the south canvas towers during their reconstruction, the presence of some residential buildings annexed to the medieval wall and the change of the perception of the space, if the citadel had been preserved up to now. Feedback from those in national and local administrations underlined the desire for a tool that can help to improve the management of cultural heritage assets (e.g., restoration planning, simulation of possible future risks) and to draw the attention of potential tourists who become fascinated by the interactive time-travel through the cultural heritage assets, together with the historical and additional information provided. 


\section{Conclusions}

Material heritage is significant for understanding the history of a place as well as, for example, attracting cultural tourism and generating economic benefits for a cultural site and the area in which it is located. Virtual heritage and multimedia exhibitions could be used as complementary to the real visit. This was one of the leading inspirational lines of the CHT2 project, providing both high-fidelity replicas of real heritage assets and historical reconstructions of heritage assets no longer existing in their original form.

Regarding the development of such virtual heritage applications, several forms of participation can be identified, in agreement with the three categories identified by Morrone (2006). The first type of participation is active and occurs before the generation of the $4 \mathrm{D}$ models, for example, by providing information useful to the creation of the virtual models or by contributing to data collection and authorizing access to private areas or documents. The second type of participation is passive and occurs after the $4 \mathrm{D}$ models are completed; it is related to attending presentations or receiving information from the $4 \mathrm{D}$ models of the heritage asset. The third type of participation is again active and can be identified as occurring when the public develops a novel affection for and interest in the heritage asset, and voluntarily participates in dissemination, new research or various cultural support projects.

Although the 4D models developed by this project specifically targeted buildings and cityscapes, typically identified as 'tangible heritage', cultural identity originates from a mix of such iconic elements and traditions, songs, dances and other non-material cultural activities, identified as 'intangible heritage'. As stated by Bouchenaki (2003),

Cultural heritage is a synchronized relationship involving society (that is, systems of interactions connecting people), norms and values (that is, ideas, for instance, belief systems that attribute relative importance). Symbols, technologies and objects are tangible evidence of underlying norms and values. Thus, they establish a symbiotic relationship between the tangible and the intangible. The intangible heritage should be regarded as the larger framework within which tangible heritage takes on shape and significance.

In the project presented here, we explored the relationship between both heritage expressions by means of $4 \mathrm{D}$ models. 


\section{References}

Anderson, B. 1983. Imagined Communities: Reflections on the Origin and Spread of Nationalism. London: Verso.

Bouchenaki, M. 2003. 'The interdependency of the tangible and intangible cultural heritage'. 14th ICOMOS General Assembly and International Symposium: Place, memory, meaning: preserving intangible values in monuments and sites, 27-31 October 2003, Victoria Falls, Zimbabwe. Accessed 10 May at https://pdfs .semanticscholar.org/baa9/83afa9412875f7732ac1652d4834b5ea854a.pdf

Buckley, A. 1998. 'Introduction. Daring us to laugh: Creativity and power in Northern Irish symbols', in A. Buckley (ed.), Symbols in Northern Ireland. Belfast: Institute of Irish Studies, Queen's University Press, 87-108.

Cameron, F. and S. Kenderdine (eds). 2007. Theorizing Digital Cultural Heritage. A Critical Discourse. Cambridge, MA: The MIT Press.

Chiabai, A., K. Paskaleva and P. Lombardi. 2013. 'e-Participation model for sustainable cultural tourism management: A bottom-up approach'. International Journal of Tourism Research 15 (1), 35-51.

Ciasullo, M.V., A. Gaeta, M. Gaeta and G. Monetta. 2016. 'New modalities for enhancing cultural heritage experience. The enabling role of digital technologies'. Sinergie 99, 119-39.

Doulamis, A., N. Doulamis, E. Protopapadakis, A. Voulodimos and M. Ioannides. 2018. '4D modelling in cultural heritage', in M. Ioannides, J. Martins, R. Žarnić and V. Lim (eds), Proceedings of the International Workshop Advances in Digital Cultural Heritage. Cham: Springer, 174-96.

Faro Convention. 2005. 'Council of Europe Framework Convention on the Value of Cultural Heritage for Society'. Council of Europe Treaty Series No. 199. Accessed 10 May at https://www.coe.int/en/web/conventions/full-list/-/conventions/rms/ 0900001680083746

Frischer, B. 2014. 'Cultural and digital memory: Case studies from the Virtual World Heritage Laboratory, Memoria Romana', in G. Karl Galinsky (ed.), Memoirs of the American Academy in Rome. Ann Arbor, MI: University of Michigan Press, 151-64.

G7. 2017. 'The protection of cultural heritage rules, practices and education'. Florence, Italy, 30 March 2017. Accessed 10 May at http://www.g7italy.it/sites/default/files/ documents/Protection_of_cultural_heritage_italian_contribution/index.pdf

Hall, S. 1999. 'Whose heritage? Un-settling "the heritage", re-imagining the Postnation' Third Text 13 (49), 3-13. https://doi.org/10.1080/09528829908576818

Harrison, R. 2013. Heritage. Critical Approaches. London: Routledge.

ICOMOS. 2018. 'European Quality Principles for Cultural Heritage Interventions'. Document produced in the framework of the EU Initiative 'Cherishing heritage: developing quality standards for EU-funded projects that have the potential to impact on cultural heritage'. Accessed 3 March 2019 at https://agcult.it/wp-content/ uploads/2018/11/For-Venice-Quality-Document-14-11-18.pdf

McDowell, S. 2008. 'Heritage, memory and identity', in The Ashgate Research Companion to Heritage and Identity. Farnham: Ashgate Publishing, 37-53.

MacDonald, S. 2013. Memorylands: Heritage and Identity in Europe Today. London: Routledge.

Morrone, A. 2006. Guidelines for Measuring Cultural Participation. Montreal, Canada: UNESCO Institute for Statistics.

Pendlebury, J. 2009. Conservation in the Age of Consensus. London: Routledge. 
Smith, L. 2006. Uses of Heritage. London and New York: Routledge.

Taylor, J. and L.K. Gibson. 2017. 'Digitisation, digital interaction and social media: Embedded barriers to democratic heritage'. International Journal of Heritage Studies 23 (5), 408-20.

UNESCO. 2011. General Conference, Resolution 15 adopted by the General Conference at its 36th session. Accessed 10 May at https://unesdoc.unesco.org/ark:/48223/ pf0000215084.page $=52$

Wright, F. and A. Falconer. 1998. Reconciling Memories. Dublin: Columba Press. 
Laura Loredana Micoli, Gabriele Guidi, Pablo Rodríguez-Gonzálvez, and Diego González-Aguilera - 9781788974639 Downloaded from PubFactory at $04 / 26 / 2023$ 12:58:05PM 